\section{Bird Biology}

Physiology and Biochemistry of the Domestic Fowl. Edited by D. J. Bell and B. M. Freeman. Vol. 1. Pp. xxii+1$602+$ cxlv. £10.50; $\$ 29.50$. Vol. 2. Pp. xxii $+603-1152+$ cxlv. $£ 10.50 ; \quad \$ 29.50$. Vol. 3. Pp. xiv $+1153-1488+$ cxlv. $£ 7.50$; \$23.50. (Academic: New York and London, December 1971.)

THESE three volumes contain material on anatomy, pathology, immunology, nutrition and various subjects other than physiology and biochemistry of fowl, by more than forty different contributors, all British. The title might better have been "Biology of birds with special reference to domestic fowl," because the volumes duplicate some of the ground to be covered in a four-volume series entitled, "Biology of Birds," to be published by Academic Press. Volume 1 is published and others will soon follow. Several chapters have similar or identical headings in the two sets of volumes. These three volumes on the domestic fowl are edited poorly. Some of the chapters are outstanding, many mediocre, and some are bad; there is duplication because many of the contributors apparently were not aware of what the others were writing.

Volume 1, twenty-four chapters, has topics on structure and function of alimentary canal, and respiration, absorption, intestinal microflora and nutrition, structure and function of kidney, energy metabolism, protein, carbohydrate and lipid metabolism, role of vitamins and trace elements, and endocrine organs except reproduction. The coverage of most of these chapters is fair to good, particularly that of anatomy, some of which-for example, that on respiration and the kidney -is outstanding. The coverage on carbohydrate metabolism and endocrines is extensive but there is some overlapping. Absorption is well done. The treatment of chapters 16-22 (endocrinology) is fair to good.

Chapters dealing with metabolism of lipids and proteins are extensive but cover a great deal on mammals, while the treatment of gaseous metabolism is fair but not extensive.

The second volume includes topics on integument, skeleton, nervous system, muscle, heart and circulation, blood corpuscles, metabolism of red cell, blood groups and coagulation, plasma enzymes, body fluids, plasma glucose, non-protein nitrogen, plasma proteins, lymphoid system, special senses, liver function, and thermo-regulation.

"Structure of Nervous System" by Bolton is sketchy but "Physiology of the Nervous System" is much better, and the chapter on pharmacological action of drugs on the central nervous system is noteworthy. Heart and blood vessel innervation might well have been integrated with chapters 31 and 32 . Both authors describe histo-fluorescent stain techniques for nerves, but apparently were unaware of what each wrote.

"The Heart" by Akester is an outstanding chapter and includes anatomy, ultrastructure and electron microscopic pictures and histo-fluorescent studies of heart (much of his own work) although he might have mentioned the work of Bennett and Malmfors. "The Vascular System," by the same author, and including cholinergic and adrenergic innervation, is particularly good and so is the treatment of the specialized circulation in kidney and liver; but the part on blood flow and cardiac output is sketchy.

The coverage on blood groups by Gilmour is good, and the Lymphoid System by Payne is extensive and deals mainly with the structure and distribution of lymphoid tissue and its role in immunogenesis.

The chapters on Metabolism of Erythrocytes, Plasma Glucose, Plasma Enzymes, and Non-Protein Nitrogen, by D. J. Bell, include much material covered elsewhere by the author in 1965 , and others but not mentioned here. "Liver Function" by Clarkson is well done, and the presentation on body temperature is fair but does not cover the review of Dawson and Hudson (1970).

Volume 3 deals in great detail with most aspects of reproduction in the domestic fowl, but the treatment is somewhat long and tedious. The principal author, A. B. Gilbert, wrote eight chapters and points out that "to condense this information into a general survey of reasonable size is formidable"; the authors have not been very successful.

Notable chapters include that on control of ovulation, "Transport of Egg Through Oviduct," "Ovulatory Cycles," and "Male Reproduction" by P. E. Lake, which is a well balanced account with an excellent compilation of information on physical and chemical composition of semen. PaUl D. Sturkie

\section{Woodlice}

Woodlice. By Stephen Sutton. Key written in collaboration with Paul Harding and David Burn. Pp. 144. (Ginn: London 1972.) £2.

THE all too rare opportunity to praise a book without reservation is one which Dr Sutton presents to the reviewer. The land-living Isopoda, commonly known as woodlice, have tended to be despised and neglected alike by academic zoologists and by collectors and amateur naturalists, in spite of their evident importance in some ecosystems. Dr Sutton's book should herald the end of such undeserved neglect. It offers, at a very reasonable price and in un- usually clear and simple English, a remarkably full summary of available knowledge of the group, including its anatomical, physiological, developmental, genetical, behavioural and ecological characteristics, while the "identification" chapter includes first-rate coloured pictures of eight of the twenty-nine native British species, together with line drawings and keys whereby it should be possible to identify almost all of the forty-two species now established in our fauna.

There is an interesting chapter on techniques for the study of woodlice, including practical instructions for a number of simple laboratory and field experiments on species of the group, many of which would be suitable for elementary courses in general biology. At the end the author explains the grid-square recording scheme now being developed for British woodlice, on which currently available distributional information is manifestly very defective. For example, Sutton records Armadillidium vulgare as "rare in Scotland", while I have found it in abundance at Burnmouth in Berwickshire, and $A$. pictum, for which Sutton notes "recent records only from the southern Lake District", is common at a number of localities along the Solway coast. The final bibliography is quite extensive, running to six pages, without, of course, pretending to be exhaustive. The weakest part of the book is perhaps the index, which does not include names of woodlouse genera, references to the species outside the "identification" chapter, or authors.

\section{R. A. Crowson}

\section{Atomic Physics}

New Directions in Atomic Physics. Vol. 1. Theory. Pp. xiii +250 . Vol. 2. Experiment. Pp. xv +163. Edited by Edward U. Condon and Oktay Sinanoğlu. (Yale University: New Haven and London, April 1972.) Vol. 1, £5.95. Vol. 2, £3.50.

THESE, two volumes contain between them seventeen review articles on a variety of topics in atomic physics. They originated as papers delivered at a NATO Advanced Study Institute in Izmir, Turkey.

All such collections risk failure to maintain a constant standard of presentation and intelligibility, and these are no exception. In volume 1 , devoted to theoretical topics, the most generally useful contributions are those of D. F Mayers on "Relativistic Self-Consistent Fields", Oktay Sinanoǧlu on "Electron Correlation in N-Electron Atoms-a New Atomic Structure Theory" and P. G. Burke on "Electron-Atom Scattering and Resonances"; this last is a model of clarity. The prize for unintelligibility 